\title{
A produtividade científica tem sexo? Um estudo sobre bolsistas de produtividade do $\mathrm{CNPq}^{*}$
}

\author{
Moema de Castro Guedes** \\ Nara Azevedo** \\ Luiz Otávio Ferreira***
}

\section{Resumo}

Análise da composição sexual, da faixa etária e da distribuição entre as áreas de conhecimento, entre 2001 e 2012, do grupo de pesquisadores bolsistas produtividade em pesquisa do Conselho Nacional de Desenvolvimento Científico e Tecnológico (CNPq). A partir de uma base de dados estatísticos fornecidos por essa agência, as principais conclusões se referem às diferenças na proporção entre homens e mulheres conforme a área de conhecimento, e ao fenômeno da juvenilização, que ocorreu em todas as áreas e favoreceu os homens.

Palavras-chave: Bolsa Produtividade em Pesquisa, Composição por Sexo, Idade, Área de Conhecimento, Cnpq.

\footnotetext{
* Recebido para publicação em 21 de novembro de 2014, aceito em 06 de agosto de 2015.

** Professora do Departamento de Ciências Sociais, da Universidade Federal Rural do Rio de Janeiro, Rio de Janeiro, RJ, Brasil.moguedes@yahoo.com.br

** Professora do Programa de Pós-Graduação em História das Ciências e da Saúde, da Fundação Oswaldo Cruz, Rio de Janeiro, RJ, Brasil. nazevedo@fiocruz.br

*** Professor adjunto do Departamento de Ciências Sociais e Educação, da Universidade do Estado do Rio de Janeiro; pesquisador titular e docente do Programa de Pós-graduação em História das Ciências e da Saúde, da Fundação OswaldoCruz, Rio de Janeiro, RJ, Brasil. lotavio@fiocruz.br
} 
368 A produtividade científica tem sexo?

Is Scientific Production Sexed? A Study of Recipients of Cnpq Productivity Scholarships

\begin{abstract}
Analysis of sexual composition, age groups and distribution amid knowledge fields, between 2001 and 2012, among researchers with productivity scholarships from the Conselho Nacional de Desenvolvimento Científico e Tecnológico ( $\mathrm{CNPq})$. Considering a statistical database provided by this agency, the major conclusions are related to the differences in the participation of men and women according to knowledge field, and the rejuvenation of scholars' profile in the last decade, which occurred in all areas and particularly favored male researchers.
\end{abstract}

Key Words: Cnpq Scholarship, Sex, Age and Areas of Knowledge of Recipientes, Cnpq. 


\section{Introdução}

O propósito neste artigo é analisar a composição sexual, a faixa etária e a distribuição entre as áreas de conhecimento, entre 2001 e 2012, do grupo de pesquisadores detentores de bolsa produtividade em pesquisa (PQ) do Conselho Nacional de Desenvolvimento Científico e Tecnológico (CNPq). ${ }^{1}$

A bolsa produtividade adquiriu crescente atração $e$ importância no meio acadêmico brasileiro a partir de meados dos anos 1990, quando se verificou um aumento do dispêndio público em atividades de ciência e tecnologia (C\&T), e a ênfase na elevação da produção científica nacional por parte do CNPq e da Coordenação de Aperfeiçoamento de Pessoal de Nível Superior (Capes), agência do Ministério da Educação (MEC) responsável pela pós-graduação no país. Nesse período, é possível observar a configuração de um sistema particular em relação tanto às demais modalidades de bolsa oferecidas pelas agências de fomento do país quanto às características que apresentava na origem, em 1976. Se naquela época já constituía um instrumento de diferenciação simbólica entre pares, na atualidade se institucionalizou como um sistema hierarquizado de posições, tipificando um perfil de excelência do que pode ser considerado uma elite científica - a de especialistas e profissionais da pesquisa, a quem se reconhece a liderança na condução das atividades de C\&T no país e se contempla com recursos materiais e simbólicos que lhes são exclusivos.

A análise dos dados estatísticos sobre a distribuição por sexo das bolsas de produtividade no período 2001-2012 revela um paradoxo. Enquanto as políticas públicas de educação e de C\&T empreendidas desde a década de 1970 impulsionaram a população feminina ao ensino superior e à pós-graduação resultando numa extraordinária reversão do desequilibrio de

1 Este artigo é um dos resultados do projeto de pesquisa "Gênero e Ciência: uma análise das mulheres nas carreiras acadêmicas a partir dos anos 1990 no Brasil", financiado pelo CNPq através do edital 32/2012. 
oportunidades educativas que historicamente favoreciam o sexo masculino -, a política que instituiu a categoria do bolsista produtividade em pesquisa não promoveu efeitos virtuosos similares no que diz respeito às mulheres, que não desfrutam de oportunidades profissionais compatíveis com sua ascensão educacional no mundo acadêmico. Apesar de oportunidades educacionais não se traduzirem espontaneamente em oportunidades profissionais, nota-se uma desproporção por sexo entre os agraciados com a $\mathrm{PQ}$, incongruente com o número $e$ o grau de qualificação acadêmica alcançados pelas mulheres nas últimas décadas.

A defasagem entre oportunidades educacionais $e$ profissionais verificada no caso da PQ constitui, a nosso ver, um efeito perverso, que produz desigualdade de gênero, cuja origem reside, provavelmente, na combinação de critérios meritocráticos que regulam a concessão e a progressão individuais na hierarquia de categorias e níveis em que se estrutura esse sistema de bolsas e critérios políticos-institucionais que definem um montante de bolsas para cada área do conhecimento.

$\mathrm{O}$ texto se divide em três seções. Na primeira, sintetizamos os princípios $e$ as regras que regulam o sistema de bolsa produtividade do CNPq. Na segunda, focalizamos os resultados apresentados na literatura recente sobre o perfil do bolsista de produtividade, com ênfase nos aspectos relacionados à sua distribuição por sexo. A terceira é dedicada aos resultados alcançados pela pesquisa com base nos dados fornecidos pelo CNPq e relativos ao período 2001-2012. Nossa análise refere-se ao número de bolsas por ano escrutinadas segundo as variáveis sexo, idade e área de conhecimento do bolsista beneficiado.

\section{Bolsa produtividade em pesquisa do CNPq: do 'título' à carreira de elite}

A bolsa produtividade em pesquisa ( $\mathrm{PQ})$ é uma entre as várias modalidades de bolsa oferecidas pelo CNPq. Apresenta a particularidade de se destinar a pesquisadores que desfrutam de 
alto reconhecimento entre seus pares ${ }^{2}$ e uma dinâmica própria de funcionamento que a distingue entre os demais tipos de bolsa oferecidos pelas agências de fomento no país.

Embora tenha sido criada em 1976, sua valorização no sistema acadêmico ampliou-se nos anos 1990, com o aumento do dispêndio público em atividades de $\mathrm{C} \& \mathrm{~T}$ e a indução explícita à elevação da produção científica nacional por parte do CNPq e da Coordenação de Aperfeiçoamento de Pessoal de Nível Superior (Capes), por meio de diferentes incentivos, dentre os quais bolsas de estímulo à pesquisa e à inovação. ${ }^{3}$ No tocante à $\mathrm{PQ}$, essas ações governamentais resultaram em um crescimento de sua concessão, que se mantém contínuo desde então: de 7.263 bolsas/ano ${ }^{4}$ em 1996 para 13.714 em 2012. ${ }^{5}$ No período 20062013, ela representou $18,75 \%$ (75.785) do total da demanda de todas as modalidades de bolsa oferecidas pelo CNPq (399.527) $e$ $21,32 \%$ no universo de 284.021 bolsas concedidas em todas as modalidades. ${ }^{6}$

A intensificação do interesse e da demanda por essa bolsa se relaciona à valorização que lhe é conferida pela política de $C \& T$ nesse contexto, traduzida em reconhecimento $e$ poder acadêmicos, evidenciados em prerrogativas exclusivas aos que a

2 A PQ é destinada a pesquisadores doutores, brasileiros e estrangeiros em situação regular no país, bem como a aposentados que mantenham vínculos com instituições de pesquisa e ensino.

3 No período 2000-2009, o dispêndio nacional em C\&T, abrangendo os setores público (federal e estadual) e empresarial, variou anualmente entre $1,30 \%$ e $1,60 \%$ do Produto Interno Bruto (PIB). Sobre o assunto ver: Oliveira $e$ Bianchetti, 2006; Hostins, 2006; Ferreira e Moreira, 2002.

${ }^{4}$ De acordo com o $\mathrm{CNPq}$, o número de bolsas/ano representa a média aritmética do número de mensalidades pagas de janeiro a dezembro.

${ }^{5}$ Quantitativos de bolsas por modalidade, tabela 2.2.6. Bolsas de produtividade em pesquisa e bolsas especiais de pesquisa: $\mathrm{n}^{\circ}$ de bolsas-ano segundo categoria $e$ nível. [www.cnpq.br/series-historicas - acesso em: 14 maio 2014.

${ }^{6}$ Cálculos feitos a partir de dados de "Demanda e atendimento por ano. Bolsas no país por área de conhecimento". [http://estatico.cnpq.br/portal/paineis/painel_bolsa_pais_area - acesso em: 14 maio 2014]. 
recebem, como, por exemplo, a de exercerem a coordenação de projetos de pesquisa, tal como exigem alguns editais de financiamento, ou funções de assessoramento em diferentes situações junto ao $\mathrm{CNPq} e$ à Capes. Outro aspecto também permite aquilatar a relevância da posse dessa bolsa: a ela podem ser vinculadas bolsas de formação de recursos humanos, destinadas a estudantes de graduação (iniciação científica) e de pós-graduação (mestrado, doutorado), e a recém-formados (bolsas de apoio técnico e de aperfeiçoamento) que atuam no projeto do pesquisador bolsista. Sua concessão implica, assim, a possibilidade de mobilização de recursos indiretos. Além da remuneração do pesquisador, ela agrega o financiamento de outras bolsas, cujos efeitos se fazem sentir diretamente na estruturação das equipes de pesquisa.

$\mathrm{O}$ instrumento legal que regula a concessão da $\mathrm{PQ}$ pelo CNPq revela algumas particularidades desse sistema ${ }^{7}$. A primeira é a estratificação em três categorias: sênior; pesquisador 1, subdividida em níveis A,B,C, D; e pesquisador $2 .{ }^{8}$ A segunda é o fato de a cada categoria corresponderem diferentes requisitos $e$ critérios para solicitação, enquadramento, prazos de vigência $e$ remuneração estipulada pela agência. $\mathrm{O} \mathrm{CNPq}$ reconhece a responsabilidade e a autonomia acadêmica do comitê assessor $(\mathrm{CA})^{9}$ da área de conhecimento à qual é submetido o projeto de pesquisa. No entanto, a avaliação da proposta deve considerar o conjunto de critérios independentes, gerais e específicos, estabelecidos pelo $\mathrm{CNPq}$, relacionados basicamente ao mérito científico do projeto e à performance do proponente quanto a relevância da produção científica, atuação contínua na formação

7 Bolsas individuais no país. Produtividade em pesquisa. Norma completa. [www.cnpq.br/CNPq - acesso em: 24 abr. 2014].

8 Essa classificação sofreu modificações ao longo do tempo. As categorias sênior e 2F foram instituídas em 2005.

${ }_{9}$ Os comitês assessores são compostos por pesquisadores reconhecidos em sua área de atuação e indicados pelo Conselho Deliberativo do CNPq, com base em, entre outros critérios, consultas às entidades científicas e aos próprios cientistas (Wainer e Vieira, 2013:62). 
de recursos humanos em nível de pós-graduação, inserção internacional e participação em atividades de gestão científica $e$ acadêmica. A maior parte dos critérios específicos a cada categoria diz respeito ao pesquisador categoria 1 , com base nos quais se diferenciam os níveis $\mathrm{A}, \mathrm{B}, \mathrm{C}, \mathrm{D}$ configurando-se um sistema de progressão e promoção em que a posição mais elevada corresponde ao nível $\mathrm{A} .{ }^{10}$ Sobre ela recaem as maiores exigências dessa categoria, definida como um perfil de liderança significativa em sua área de pesquisa. Outro aspecto que se depreende da estratificação resultante desse conjunto de critérios definidos pela agência é a distinção conferida à categoria sênior, situada no topo da hierarquia, acessível a penas ao pesquisador que comprovar a posse anterior de PQ na categoria 1 níveis $\mathrm{A}$ ou $\mathrm{B}$ por, no mínimo, 15 anos, consecutivos ou não.

A terceira característica do sistema de PQ é a dinâmica que rege o processo de enquadramento e progressão nas categorias $e$ níveis. A cada julgamento, a Diretoria Executiva da agência estabelece uma cota de PQ por categoria para cada CA, definindo, por conseguinte, um número fixo de PQs por área. ${ }^{11}$ Estabelecidos esses parâmetros e respeitados os critérios definidos pela agência, o $\mathrm{CA}$, com base em seus próprios critérios, procede à classificação das PQs em categorias, recomenda a progressão ou o rebaixamento de nível, e até mesmo a exclusão do sistema. ${ }^{12} \mathrm{~A}$ progressão entre os níveis da categoria pesquisador 1 depende do julgamento do CA e não de cotas, embora deva ser respeitada para a categoria $1 \mathrm{~A}$ a cota máxima de $10 \%$ do total das PQs de cada "programa básico". Já o acesso da categoria pesquisador 2 à

\footnotetext{
${ }^{10}$ Para o pesquisador categoria 1 está previsto um adicional de bancada que é opcional, e cujos recursos devem ser aplicados exclusivamente em despesas relacionadas ao projeto de pesquisa ou dele decorrentes.

${ }^{11}$ Essa regra impede a distribuição livre e aleatória por parte dos CAs: uma PQ categoria 1 nível $\mathrm{C}$ só poderá ser atribuída a um pesquisador se outro houver perdido bolsa similar na mesma avaliação (Wainer e Vieira, 2013:64).

12 Somente no caso da categoria sênior as propostas são submetidas a instância superior da agência, a Diretoria Executiva, que aprecia a avaliação do CA e a encaminha para a homologação do Conselho Deliberativo.
} 
categoria pesquisador 1 , uma vez completadas as cotas de bolsa da categoria 1, pode ocorrer com a sobra de bolsas de pesquisadores categoria 1 que por algum motivo tenham sido excluídos do sistema, ou promovidos à categoria sênior, ou ainda removidos para a categoria $2 .{ }^{13}$

A essa dinâmica de enquadramento e progressão agrega-se uma terceira característica, relativa ao processo de avaliação de mérito científico. Estudos sobre esse processo assinalam a influência dos indicadores bibliométricos para qualificar a produção científica em diferentes dimensões: desde o número total de artigos publicados durante a carreira ou em determinado período, passando pela qualidade do veículo de publicação ${ }^{14}$, até a média de citações por artigo, que avalia a repercussão da produção de um pesquisador em sua área. ${ }^{15}$

Wainer e Vieira (2013:65) observam, em sua pesquisa sobre os pesquisadores de todas as grandes áreas cujas PQs foram renovadas ou modificadas em 2010, a aplicação de outros indicadores para avaliar a performance científica do candidato e/ou bolsista produtividade em pesquisa, tais como a métrica histórica referida à idade científica (número de anos desde a obtenção do doutorado) e as métricas que combinam informações sobre produtividade e impacto acumulado. Constatam também que o recurso a esses indicadores não é uniforme, e depende das

\footnotetext{
${ }^{13}$ Analisando esse processo, Wainer e Vieira (2013:64) assinalam que há restrições para se atribuir $P Q s$ de níveis mais altos a pesquisadores mais jovens em idade científica (tempo de conclusão do doutorado). Além disso, em geral as avaliações finais resultam em manutenção ou perda da PQ e na ascensão ou rebaixamento de um nível. Apenas em poucas subáreas o pesquisador sobe ou desce mais de um nível.

${ }^{14}$ As principais referências para avaliação da qualidade dos periódicos são as informações da base da Thomson Reuters (antiga ISI) e da base de periódicos Qualis-Capes.

${ }^{15}$ Nos últimos anos, destaca-se dentre esse tipo de medida, o índice $\mathrm{h}$ - o número de documentos publicados de um pesquisador com pelo menos $h$ citações cada. A medida busca evidenciar a visibilidade científica de um pesquisador, por meio da relação entre o valor de seu índice h e sua reputação, conforme a avaliação por pares (Lima, Velho, Farias, 2012:7-8).
} 
áreas de conhecimento, que apresentam práticas de comunicação científica distintas, subjacentes a culturas acadêmicas historicamente desenvolvidas. E verificam, não obstante as diferenças das áreas, uma correlação entre a aplicação desses indicadores e a distribuição de PQs pelas diferentes categorias $e$ níveis (Wainer e Vieira, 2013:76).

Essas constatações são confirmadas por Lima, Velho e Faria (2012:11-14) em investigação sobre o índice h da categoria pesquisador 1 níveis $\mathrm{A}$ e $\mathrm{B}$ das áreas de Física, Genética, Agronomia e Sociologia, pertencentes a centros de pesquisa do estado de São Paulo. Os autores verificaram a convergência entre os valores de índice h e o julgamento por pares em todas essas áreas, exceto na Sociologia, que apresenta valores h quase nulos. $\mathrm{E}$ observaram que os valores $\mathrm{h}$ mais altos nas três áreas correspondem à categoria pesquisador 1 nível $\mathrm{A}$, decrescendo para os da categoria pesquisador 1 nível $\mathrm{B}$.

Outra faceta do processo de avaliação da $\mathrm{PQ}$ diz respeito a possíveis diferenças na forma como os CAs a concebem, notadas por Wainer e Vieira (2013:67,74): como prêmio à qualidade e à relevância do trabalho de um cientista ou como incentivo à produção de qualidade. Na primeira alternativa, o histórico da performance é o fator relevante, e as métricas de impacto devem ter alta correlação com a decisão de atribuir a bolsa a um pesquisador. $\mathrm{Na}$ perspectiva do incentivo à produção de qualidade, o futuro é o mais importante, sendo o passado apenas um instrumento para prever adiante, e o agraciado deve pelo menos manter a mesma produção que resultou na concessão da bolsa, sob pena de perdê-la.

Por fim, é possível constatar uma peculiaridade da categoria pesquisador 1 nível A: sua mobilidade é quase nula. Wainer $e$ Vieira (2013:76) observaram essa tendência em seu estudo sobre o processo de concessão de $\mathrm{PQ}$ em 2010. Na análise das métricas que apresentam maior correlação com as decisões de aumento, manutenção e rebaixamento de nível nessa categoria, verificaram que as variações nos níveis ocorreram mais no nível $1 \mathrm{D}$ do que no $1 \mathrm{~A}$, sugerindo que, alcançado este último nível, o pesquisador 
adquire estabilidade maior do que os demais dos outros níveis dessa categoria.

Os dados disponíveis no $\mathrm{CNPq}$ sobre as bolsas produtividade refletem essas constatações sobre o padrão seletivo de segmentação da $\mathrm{PQ}$, configurando o sistema com uma base alargada e um topo reduzido. Entre 2001 e 2012, como mostra o Gráfico 1, verifica-se grande diferença em números absolutos na distribuição de $\mathrm{PQ}$ entre as categorias 1 e 2. Enquanto esta última, por meio da qual se efetiva o ingresso no sistema, concentra a maioria das $\mathrm{PQ}$ se esboça um intenso crescimento, mais que dobrando o contingente de bolsistas, a categoria 1 detém um pequeno montante que se mantém estável ao longo do período.

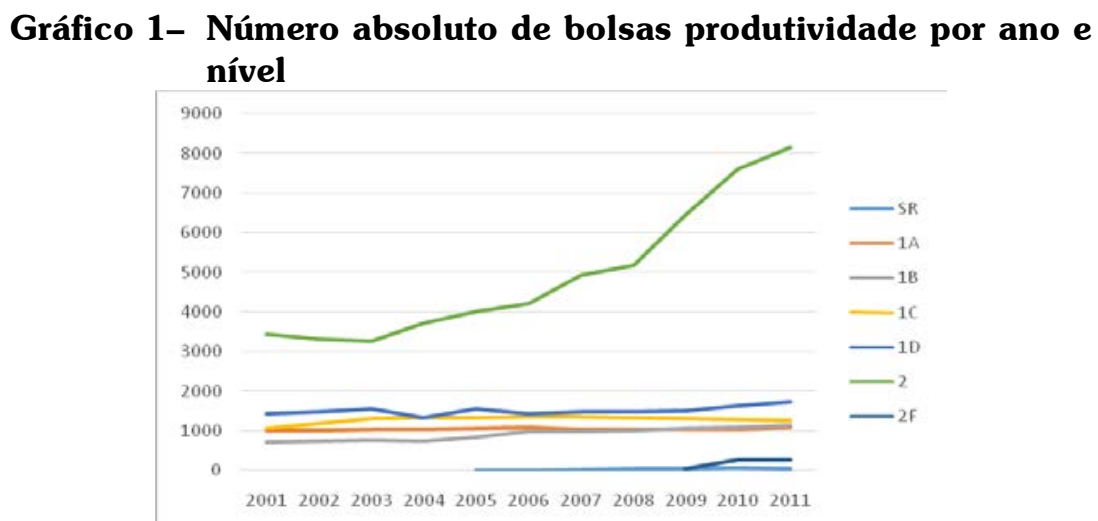

Fonte: $\mathrm{CNPq} / \mathrm{AEI}$. Elaboração própria.

O conjunto de características até aqui apontadas permite dizer que a PQ configura um sistema particular dentre as diversas modalidades de bolsas oferecidas pelas agências de fomento à pesquisa no país. Embora desde sua criação se mantenha como um instrumento de diferenciação simbólica entre pares, percebe-se uma alteração sensível de status, que evoluiu de um "título" na origem para se instituir como uma carreira, um sistema hierarquizado de posições, que tipifica um perfil de excelência do 
que pode ser considerado uma elite científica - a de especialistas e profissionais da pesquisa. ${ }^{16}$

Esse argumento fundamenta-se na constatação do caráter seletivo e restritivo do funcionamento desse sistema de bolsas, presidido pela hierarquização e por limitada mobilidade. Essa dinâmica opera produzindo e reproduzindo uma lógica distintiva, de modo a instituir a PQ como uma espécie de dote destinado a poucos que, quanto mais escasso, maior valor simbólico adquire no sistema acadêmico. ${ }^{17} \mathrm{~A}$ deliberada limitação do número de bolsas e a mobilidade quase nula no topo da hierarquia - a categoria pesquisador 1 , níveis $\mathrm{A}$ e $\mathrm{B}$ - podem ser interpretadas nessa perspectiva de análise. ${ }^{18}$ Esse é o "lugar" de uma categoria especial: a elite da elite.

\section{O bolsista produtividade em pesquisa do CNPq: um inventário dos perfis em diferentes áreas de conhecimento}

Vários estudos realizados nos anos 2000 sobre o perfil do bolsista produtividade em pesquisa do CNPq constatam em diferentes áreas de conhecimento uma flagrante desigualdade entre homens e mulheres. A desproporção favorável ao sexo masculino relatada nesses estudos não encontra equivalência no ensino superior e na pós-graduação, em que, em geral, se constata um avanço na participação feminina nas últimas três décadas, quando não um equilíbrio na composição por sexo. ${ }^{19}$ Se a

\footnotetext{
${ }^{16} \mathrm{O}$ termo elite é utilizado aqui em sentido amplo para marcar as distinções sociais desse grupo profissional entre os cientistas brasileiros. Sobre a atual perspectiva da história das elites, ver Heinz, 2006.

${ }^{17}$ Sobre os processos de estratificação social nas ciências ver Merton, 2013 e Bourdieu, 1983.

${ }^{18}$ Nesse sentido, a PQ pode ser entendida como capital científico e integra a luta simbólica pela autoridade científica (Bourdieu, 1983).

${ }^{19} \mathrm{O}$ caso da titulação de doutores é emblemático dessa nova realidade. A partir de 2004, quando ocorreu a inversão da tendência histórica, segundo a qual a maioria dos doutores era composta por homens, o número de mulheres tituladas foi superior ao de homens, atingindo, em 2008, a proporção de 51,5\% de mulheres e 48,5\% de homens (Doutores, 2010:41).
} 
mudança na participação feminina na $C \& T$ brasileira tem largo alcance, como explicar a resistência do padrão tradicional de distribuição por sexo, segundo o qual o sexo masculino é predominante, no âmbito de um sistema que concentra a elite científica do país?

Baseados em informações extraídas dos currículos Lattes dos pesquisadores, os estudos disponíveis sobre o perfil do bolsista produtividade em pesquisa abrangem algumas das áreas que compõem as grandes áreas de conhecimento, tal como definidas pelo $\mathrm{CNPq}$ e pela Capes. Desenvolvem análises estatísticas de caráter transversal e descritivo, contemplando, com diferentes ênfases, principalmente as variáveis formação acadêmica (graduação e pós-graduação), área de atuação, indicadores bibliométricos da produção científica, quantitativo e distribuição das bolsas por categorias e níveis, e por sexo. Embora não aprofundem a investigação sobre as razões da distribuição desigual por sexo, limitando-se, em geral, a constatá-la, esses inventários oferecem informações relevantes e indícios que podem contribuir para um entendimento preliminar da desproporção na composição por sexo desse contingente de bolsistas.

A grande área de CIÊNCIAS DA SAÚDE é a única inventariada mais amplamente, identificando-se estudos sobre a Saúde Coletiva, Medicina, Odontologia e Educação Física. Destaca-se nesse conjunto a investigação pioneira de Barata e Goldbaum (2003:1.865), que analisaram o perfil de 115 pesquisadores da área de Saúde Coletiva, na qual o contingente feminino era maioria (59\%), com concentração de mulheres (51\%) na categoria pesquisador 2, patamar de ingresso no sistema da $P Q$. Já os bolsistas do sexo masculino eram predominantes na categoria pesquisador 1 (A,B,C,D), destinada aos pesquisadores de reconhecida "maturidade" científica. $\mathrm{Na}$ categoria sênior encontravam-se apenas dois pesquisadores, um homem e uma mulher, anulando-se o sexo como fator de diferenciação. Apesar de não oferecerem uma explicação para a distribuição equilibrada por sexo na saúde coletiva, Barata e Goldbaum deixam uma pista importante: essa área se caracteriza por uma composição híbrida, 
apresentando um caráter "interdisciplinar, politemático, e limites amplos e pouco definidos" (2003:1.866).

Focalizando a mesma área em período posterior, Santos et al. (2009:765) constataram uma "similaridade de gêneros masculino e feminino" ao analisarem os dados de 155 pesquisadores. A proporção observada entre os sexos - mulheres $50 \%$ e homens $49 \%$ - era praticamente igual. A maioria desse agrupamento (48\%) se concentrava na categoria pesquisador $2, e$ já não havia nenhuma bolsa categoria sênior.

$\mathrm{Na}$ Medicina, em contraste com a Saúde Coletiva, a distribuição das PQs se apresentou amplamente favorável aos homens em estudo conduzido por Mendes et al. (2010:536). Analisando um grupo de 383 pesquisadores, constataram que a maioria (66\%) pertencia ao sexo masculino, que constituía a maioria em todas as categorias.

Não obstante os autores atribuírem a "prevalência de bolsistas do gênero masculino" à inserção tardia das mulheres no mundo da ciência e às suas dificuldades em conciliar a carreira científica com a vida familiar e a maternidade, cabe atentar para um aspecto importante desse campo de conhecimento: a subdivisão em 38 áreas de especialidades. É provável que tal fragmentação influencie a desproporção na distribuição das PQs entre os sexos, como sugere o estudo específico sobre o perfil dos bolsistas produtividade em Cardiologia: de um universo de 411 pesquisadores em Medicina, 33 são especialistas em Cardiologia e, desses, 73\% eram do sexo masculino (Oliveira et al., 2011:188). Ou seja, a desigual distribuição por sexo entre os bolsistas de produtividade em Medicina pode resultar da fragmentação interna dessa área e do montante de PQs destinado a algumas especialidades.

$\mathrm{Na}$ Odontologia, a distribuição por sexo é similar à observada em Medicina. No universo de 132 bolsistas produtividade estudado por Cavalcante et al. (2008:108), os pesquisadores do sexo masculino constituem a maioria (64\%).

O pequeno grupo de 75 bolsistas produtividade da área de Educação Física apresenta característica similar, concentrando-se 
na PQ categoria pesquisador $2(67 \%)$ e formando uma maioria masculina (75\%) (Leite et al., 2012:92).

O artigo de Santos, Cândido e Kupens (2010:492) sobre a Química, o único identificado sobre uma especialidade da grande área de CIÊNCIAS EXATAS E DA TERRA, revela que o sexo feminino compunha apenas $32,8 \%$ do total das bolsas dessa área, o que correspondia à média geral $(33 \%)$ de distribuição de PQs entre as mulheres em todas as áreas de conhecimento em 2008.

$\mathrm{Na}$ grande área de CIÊNCIAS AGRÁRIAS foi identificada a investigação sobre o perfil do bolsista produtividade em Medicina Veterinária. Spilki (2013:207) constatou que dos 304 pesquisadores, a maioria $(72 \%)$ era do sexo masculino. Em todas as categorias de $\mathrm{PQ}$ a participação feminina variava de $20 \%$ a $30 \%$, com exceção da bolsa categoria pesquisador $2 \mathrm{~F}$, em que se elevava para $40 \%$.

A grande área das ENGENHARIAS é outro caso emblemático de disparidade de composição por sexo, identificada por Alves, Yanasse e Soma (2011). No grupo de 186 pesquisadores bolsistas das áreas de Engenharia de Produção e de Engenharia Operacional foi encontrada distribuição por sexo totalmente favorável aos homens $(71 \%)$, concentrados na categoria pesquisador 2 . O peso da presença dos homens nessa categoria é o fator que desequilibra a distribuição entre os sexos.

Não surpreende que a distribuição por sexo dos 297 pesquisadores com PQ em Psicologia (Wendt et al., 2013:541), tradicional nicho feminino no âmbito das CIÊNCIAS HUMANAS, seja desequilibrada em favor das mulheres (63\%). A distribuição por sexo segundo as categorias de $\mathrm{PQ}$ repete o mesmo padrão já observado em outros casos: concentração na categoria pesquisador 2 (58\%). A expressiva presença feminina nessa categoria lhe confere a vantagem na área, tal como ocorre na Saúde Coletiva, enquanto nas demais categorias verifica-se um equilibrio entre os sexos.

Embora a maioria desses trabalhos se limite a constatar a disparidade da distribuição por sexo, desfavorável à participação feminina, alguns argumentam que esse fenômeno reproduz a 
posição subalterna das mulheres na vida privada e no mundo do trabalho. Ainda que tal explicação seja plausível, a metodologia adotada por esses estudos não permite saber se a inserção acadêmica e profissional das mulheres foi tardia, nem se a dinâmica da vida privada impacta negativamente o desenvolvimento da carreira. Por outro lado, apesar das limitações metodológicas e da restrita abrangência, é possível deduzir desse inventário algumas conclusões que podem contribuir para a reflexão sobre o assunto.

A primeira é a de que a predominância masculina ou feminina na distribuição das $\mathrm{PQs}$ está diretamente relacionada ao peso de cada sexo na categoria pesquisador 2 , patamar inicial da "carreira" que concentra a maioria das PQs em todas as áreas analisadas. Naquelas em que as mulheres constituem a maioria entre os "iniciantes" constata-se o equilíbrio e/ou a predominância feminina, como no caso da Saúde Coletiva e da Psicologia. Em casos como o da Medicina Veterinária ou das engenharias de Produção e Operacional, em que os homens são maioria consolidada nas categorias 2 , o fenômeno é oposto, não se vislumbrando um equilíbrio a médio e longo prazos.

É possível inferir também que não existe um único perfil, mas sim diversos perfis de acordo com a área de conhecimento, inclusive no tocante à variável sexo. Explorar essa pista significa indagar em que medida essa diversidade se relaciona a características institucionais de cada área - montante de bolsas, subdivisão em especialidades, natureza interdisciplinar, entre outras- e como essas características incidem sobre a distribuição desigual entre os sexos, desfavorável às mulheres, no âmbito da $\mathrm{PQ}$.

\section{Sexo e idade dos bolsistas produtividade em pesquisa: rupturas e continuidades nos perfis}

Apresentamos aqui a distribuição da $\mathrm{PQ}$ em números absolutos, segundo as variáveis sexo, idade $e$ área de conhecimento do bolsista, agregada a partir da classificação de 
pós-graduações criada pela Capes. ${ }^{20}$ Nossa intenção é demonstrar se e onde ocorreram mudanças no perfil do bolsista produtividade no período 2001-2012, e apontar possíveis rupturas e continuidades no processo de ingresso do contingente feminino nesse seleto grupo de pesquisadores brasileiros.

Os dados que configuram as tendências e padrões aqui analisados foram extraídos de um banco de dados disponibilizado pelo $\mathrm{CNPq}^{21}$ no programa Excel, cuja unidade de análise fundamental é o montante de bolsas/ano ${ }^{22}$ em cada grande área de conhecimento (formadas por áreas de conhecimento), segundo categoria/nível hierárquico da $\mathrm{PQ}$, sexo e idade do bolsista contemplado com o benefício. Para fins de melhor comparabilidade e visualização dos processos em curso, foi somado inicialmente o número total de PQs de todas as áreas de conhecimento, sem discriminar categorias/níveis ${ }^{23}$, o que possibilitou perceber com mais clareza as mudanças relativas ao sexo e à idade dos bolsistas. Em um segundo momento, a análise foi feita por área de conhecimento, visando identificar as tendências que se destacavam seja pela magnitude, seja por se afastarem das médias anteriormente descritas. ${ }^{24}$ Desse modo

${ }^{20}$ Em estudo sobre o total de 8.197 bolsistas do CNPq, cadastrados em 1998, Olinto (2003) utiliza as variáveis sexo e idade para a análise de bolsistas produtividade em pesquisa, que representavam $92,8 \%$ desse universo.

${ }^{21}$ Destacamos a imensa colaboração do setor de estatística do $\mathrm{CNPq}$, que disponibilizou prontamente o conjunto de dados necessários à construção das questões aqui analisadas.

${ }^{22}$ Como o número de bolsas-ano representa a média aritmética do número de mensalidades pagas de janeiro a dezembro, os pesquisadores contemplados não são necessariamente os mesmos indivíduos de um ano para o outro, e, frequentemente, a $\mathrm{PQ}$ não foi disponibilizada durante $\mathrm{o}$ ano inteiro. Nesses casos, os valores aparecem fracionados.

${ }^{23}$ Com esse procedimento, alguns números absolutos de $\mathrm{PQ}$ das grandes áreas de conhecimento se distinguem em um patamar mínimo dos dados agregados apresentados no site do CNPq.

${ }^{24} \mathrm{O}$ tratamento de parte desses dados contou com a colaboração de Jessika Martins Ribeiro, que atua como bolsista de Iniciação Tecnológica e Industrial 
estruturadas, as informações permitem visualizar uma ampla gama de questões: 1) a segmentação na oferta de PQs segundo área de conhecimento; 2) a evolução da oferta de PQs no período 20012012, com identificação das áreas nas quais houve maior expansão; 3) o diferenciado peso relativo das PQs concedidas para mulheres dependendo da área; 4) perfil etário dos bolsistas, com identificação das áreas nas quais há maior presença de jovens; 5) o diferenciado peso relativo das $\mathrm{PQs}$ concedidas para mulheres dependendo das idades em cada área.

As grandes áreas são apresentadas em ordem decrescente em relação ao seu peso dentro do conjunto de PQs. ${ }^{25}$ Nesse sentido, chamamos a atenção para os distintos patamares apresentados nos gráficos. Outro procedimento importante para a análise foi considerar a idade de 50 anos como ponto de corte que distingue os bolsistas mais jovens, uma vez que o benefício só é concedido a pesquisadores com larga experiência e produção acadêmicas, dimensões dificilmente alcançadas logo após a conclusão da pós-graduação.

\subsection{A distribuição de bolsistas por grandes áreas de conhecimento}

As CIÊNCIAS EXATAS E DA TERRA destacam-se como grande área que detém, com larga vantagem, o maior número de PQs no país - 1.775 em 2001 e 3.090 em 2012 (crescimento de 74\% em um patamar já bastante elevado). Esse alto peso relativo faz com que suas dinâmicas determinem em grande medida o desenho geral dos dados quando analisados de modo agregado. Destaca-se nesse conjunto o altíssimo peso da Física, maior contemplada em

(ITI/CNPq) no projeto Gênero e Ciência: uma análise das mulheres nas carreiras acadêmicas a partir dos anos 1990 no Brasil.

${ }^{25}$ A área MULTIDISCIPLINAR não foi contemplada pela análise em função da inexistência de dados para o início do período analisado (2001) e dos patamares muito baixos de bolsistas em todas as idades em 2012. Destacamos apenas que nesse montante (198 PQs em 2012), 65\% são masculinas e 35\% femininas. 
384 A produtividade científica tem sexo?

patamares bastante superiores (571,6 em 2001 e 877,6 em 2012) ao de qualquer outra disciplina desde a criação da $\mathrm{PQ}$ e a única a apresentar um bolsista com menos de 30 anos.

\section{Gráficos 2 e 3- Número absoluto de bolsas produtividade em Ciências Exatas e da Terra ${ }^{26}$, segundo sexo e idade do bolsista}

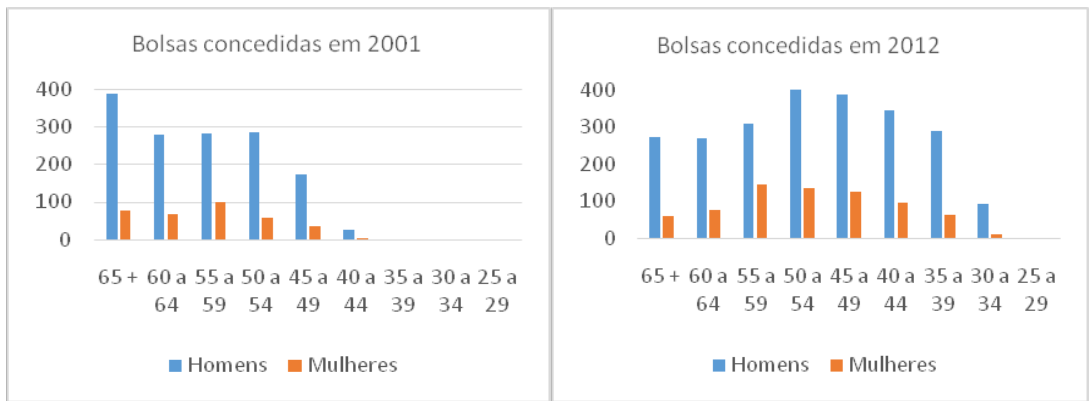

Fonte: $\mathrm{CNPq} / \mathrm{AEI}$. Elaboração própria.

A mudança de formato do Gráfico 2 para o 3 evidencia a tendência de rejuvenescimento dos bolsistas, bastante intensa particularmente para o grupo masculino. Em termos gerais, o peso dos bolsistas mais jovens (menos de 50 anos) passa de 13,4\% a $45,7 \%$. É o perfil mais jovem entre todas as grandes áreas pesquisadas. Apesar de as PQs se concentrarem nos grupos etários de 45 a 54 anos, o peso relativo dos bolsistas de 40 a 44 anos e até mesmo daqueles de 35 a 39 anos é bastante alto se comparado ao das demais áreas analisadas.

Outro elemento marcante é que apesar do altíssimo contingente de PQs, as mulheres apresentam peso relativo bastante reduzido, tendência que não parece mudar muito ao longo do tempo. A participação feminina aumentou pouco no período, passando de 19,1\% em 2001 para 23,3\% em 2012. No contingente mais jovem, a proporção de mulheres não aumenta

\footnotetext{
${ }^{26}$ Composta por: Astronomia, Ciência da Computação, Ciência da Informação, Ciência e Tecnologia de Alimentos, Física, Geociências, Matemática, Probabilidade e Estatística, Química.
} 
muito, e atinge $21 \%$ em 2012 . Isso explica em parte a percepção de um quadro estagnado em termos de presença feminina ao se agregar os dados, uma vez que o peso relativo dessa grande área é altíssimo no montante total de PQs.

Nas áreas que compõem as CIÊNCIAS EXATAS E DA TERRA ocorre certa diversidade nos dados. Enquanto algumas são marcadamente masculinas (menos de um terço das PQs são concedidas a pesquisadoras mulheres) e avançam muito pouco ou mesmo regridem na última década - Astronomia, Ciência da Computação, Física, Geociências e Matemática -, em outras percebemos claro crescimento da presença feminina (ainda que as mulheres continuem em minoria). É o caso da Química e da Probabilidade e Estatística. Na subárea de Ciência e Tecnologia de Alimentos, as mulheres revertem a desvantagem do início do período analisado (2001) e passam a ser maioria dos bolsistas de produtividade em 2012. A única área majoritariamente feminina, e que assim permanece, é a Ciência da Informação, que também se destaca pelo reduzido montante de PQs (apenas 45, das quais 34 são de mulheres).

A segunda maior grande área em relação ao montante de PQs, as ENGENHARIAS, também se destaca historicamente como um tradicional reduto masculino. O grande aumento do número de PQs - de 1.159 em 2001 para 2.101 em 2012 - favoreceu principalmente os bolsistas jovens. Isso se reflete no aumento substancial do peso relativo dos mais jovens (menos de 50 anos): de $8 \%$ para $38,6 \%$ no fim do período. Cabe salientar que o peso do grupo etário 45 a 49 anos já era relativamente alto em 2001. Em contrapartida, os mais velhos perdem claramente o peso que tinham anteriormente, como evidencia a mudança de forma do Gráfico 4 para o 5.

No entanto, esse crescimento foi maior entre os pesquisadores homens. Os dados mostram que a abertura de determinado campo científico aos pesquisadores jovens nem sempre se relaciona diretamente ao aumento da presença feminina. Os gráficos evidenciam crescimento na proporção de bolsistas mulheres ao longo do período analisado. Em relação a 
386 A produtividade científica tem sexo?

esse montante agregado, as mulheres passaram de $14 \%$ para $18,8 \%$ no fim de período analisado. No contingente de pesquisadores com menos de 50 anos as mulheres são 19,5\% dos bolsistas, patamar bastante próximo ao do contingente total.

\section{Gráficos 4 e 5 - Número absoluto de bolsas produtividade em Engenharias $^{27}$, segundo sexo e idade do bolsista}

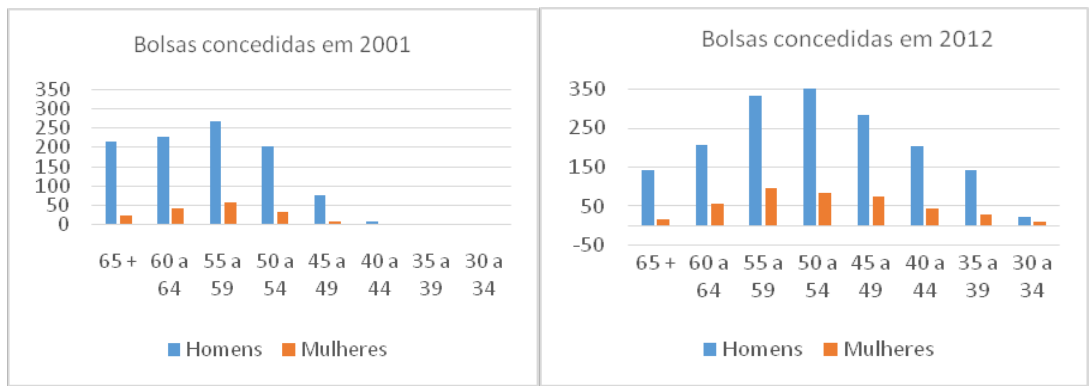

Fonte: $\mathrm{CNPq} / \mathrm{AEI}$. Elaboração própria.

Apesar de o conjunto de dados das ENGENHARIAS ser bastante homogêneo no que tange à baixa presença feminina $e$ ao pequeno aumento verificado, alguns casos destoam dos demais, cujo expressivo montante de PQs delineia uma clara feminização: Engenharia Sanitária (13,9\% para 30,9\% do total de bolsistas), Engenharia Química (29,8\% para $39,7 \%)$ e Engenharia de Produção (18,2\% para 27,4\%). Dentre aquelas que apresentaram aumento da presença feminina um pouco superior ao da média da grande área, destacam-se a Engenharia Civil e a Engenharia de Materiais e Metalurgia. Em contrapartida, na Engenharia Elétricavemos um retrocesso no já baixo patamar na proporção de mulheres: de $4,9 \%$ para $3,3 \%$.

${ }^{27}$ Composta por: Engenharia Aeroespacial, Engenharia Agrícola, Engenharia Biomédica, Engenharia Civil, Engenharia de Materiais e Metalúrgica, Engenharia de Minas, Engenharia de Produção, Engenharia de Transportes, Engenharia Elétrica, Engenharia Mecânica, Engenharia Naval e Oceânica, Engenharia Nuclear, Engenharia Química, Engenharia Sanitária, Engenharia/ Tecnologia/Gestão, Planejamento Energético, Microeletrônica. 
Como terceira grande área em montante de PQs, as CIÊNCIAS BIOLÓGICAS apresentavam em 2001 alta presença feminina: 44\%. Esse quadro se mantém ao fim do período, passando o peso relativo das bolsistas mulheres para $46,1 \%$. No segmento com menos de 50 anos, as mulheres têm peso relativo menor que no geral: são 40,7\% dos bolsistas.

\section{Gráficos 6 e 7 - Número absoluto de bolsas produtividade em Ciências Biológicas ${ }^{28}$, segundo sexo e idade do bolsista}

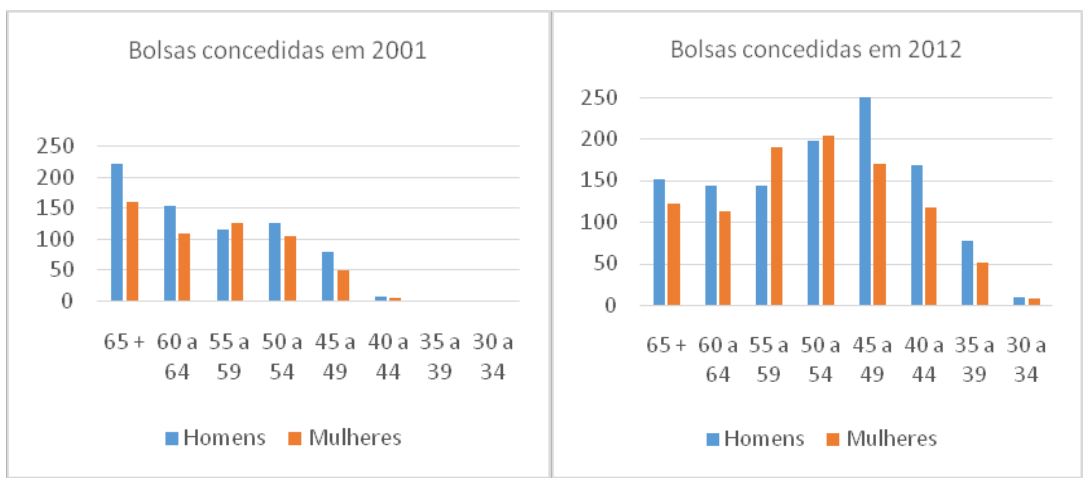

Fonte: $\mathrm{CNPq} / \mathrm{AEI}$. Elaboração própria.

O que de fato chama a atenção nesse conjunto de dados é o rejuvenescimento dos bolsistas. Em linhas gerais, o grupo com menos de 50 anos cresce de $11,3 \%$ para $40,3 \%$. Isso se reflete no alto peso relativo dos grupos etários de 35 a 39 e de 40 a 44 . A significativa redução no número de bolsistas mais velhos (com mais de 60 anos) também é outro dado relevante.

Nessa área o crescimento relativo entre 2001 e 2012 foi de 63\%, passando de 1.261 PQs em 2001 para 2.016 no fim do período. Como conjunto, os dados das CIÊNCIAS BIOLÓGICAS são bastante heterogêneos. Essa grande área é composta por ampla gama de áreas, desde as mais tradicionais da pesquisa científica

\footnotetext{
${ }^{28}$ Composta por: Bioética, Biofísica, Biologia Geral, Bioquímica, Biotecnologia, Botânica, Fisiologia, Genética, Ecologia, Imunologia, Microbiologia, Morfologia, Oceanografia, Parasitologia, Zoologia.
} 
388 A produtividade científica tem sexo?

no país, como Botânica e Microbiologia (ambas com maioria feminina desde 2001) ${ }^{29}$, até áreas de grande expansão e valorização recente, como Genética e Bioquímica - a primeira com ligeira vantagem feminina desde 2001 e a segunda com pequena desvantagem para as mulheres no final do período analisado. Nesse conjunto, apenas três continuam com diferenças expressivas favoráveis aos bolsistas homens em 2012: Ecologia, Oceanografia e Zoologia. ${ }^{30}$ Nas demais áreas os patamares são bastante próximos entre os bolsistas de ambos os sexos.

Nas CIÊNCIAS DA SAÚDE as PQs aumentaram de 889 em 2001 para 1.689 em 2012 - crescimento de 90\%, maior que a média das áreas pesquisadas. Por se tratar de uma grande área na qual muitas áreas são historicamente femininas, ligadas a trabalhos de cuidado, esse conjunto de dados é marcado pelo equilibrio entre bosistas homens e mulheres.

\section{Gráficos 8 e 9 - Número absoluto de bolsas produtividade em Ciências da Saúde ${ }^{31}$ segundo sexo e idade do bolsista}

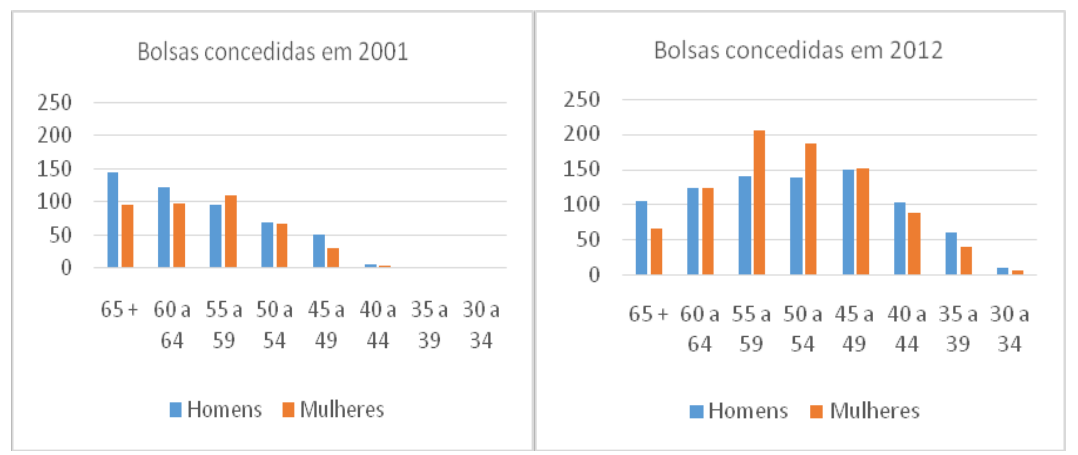

Fonte: $\mathrm{CNPq} / \mathrm{AEI}$. Elaboração própria.

${ }^{29} \mathrm{~A}$ Botânica apresenta pequena diminuição no número de mulheres no período: de $59,8 \%$ para $55,8 \%$.

${ }^{30}$ A Biofísica, área com apenas 75 PQs em 2012, também se destaca pela reduzida presença feminina.

${ }^{31}$ Composta por: Educação Física, Enfermagem, Farmácia, Farmacologia, Fisioterapia e Terapia Ocupacional, Fonoaudiologia, Medicina, Nutrição, Odontologia, Saúde Coletiva. 
A presença feminina reverte uma pequena desvantagem inicial $(45,4 \%)$ em 2001 e alcança $51 \%$ no final de período. Outra marca desse contingente de bolsistas é a tendência de rejuvenescimento, verificada em outras áreas, destacando-se, contudo, uma singularidade: a maior expansão do contingente feminino nas idades intermediárias. A perda de peso dos pesquisadores mais velhos é significativa tanto para homens quanto para mulheres. O peso relativo dos pesquisadores mais jovens (com menos de 50 anos) passa de $10,2 \%$ para $35,8 \%$ em 2012. No entanto, o peso feminino cai ligeiramente no grupo mais jovem, chegando a $47 \%$ do montante total de PQs. Nesse sentido, é fundamental destacar que as mulheres só passam a ser maioria a partir do grupo etário 45 anos ou mais, e, entre os pesquisadores com mais de 65 anos, a ampla maioria é homem.

Essa grande área também é marcada por ampla diversidade de tendências nas áreas que a compõem. Dentre os históricos redutos femininos aparecem Enfermagem (área mais feminizada dentre todas as pesquisadas com mais de 100 PQs, com 95,7\% de bolsistas mulheres), Farmácia, Fisioterapia e Terapia Ocupacional, Fonaudiologia e Nutrição. A Medicina se destaca como campo historicamente masculino, valorizado socialmente, no qual o crescimento da proporção de mulheres ao longo do período chama a atenção: de 29,5\% em 2001 para 35,3\% em 2012. Dentre as áreas caracterizadas pelo equilíbrio constam a Saúde Coletiva e a Farmacologia, ambas com pequena vantagem masculina em 2001, mas revertida em 2012, quando as pesquisadoras constituem a maioria. A área de Odontologia continua marcadamente masculina, e a Educação Física, que já apresentava grande vantagem masculina em 2001, amplia essa proporção no final da série analisada.

A grande área de CIÊNCIAS AGRÁRIAS, tradicional reduto masculino, apresenta claro rejuvenescimento dos bolsistas. $\mathrm{O}$ peso relativo dos bolsistas com menos de 50 anos passa de 7,7\% em 2001 para $37,6 \%$ em 2012 . Isso se reflete no fato de o grupo etário com mais PQs em 2012 ser o de pesquisadores de 45 a 49 anos, tratando-se, provavelmente, de bolsas 2 e $2 \mathrm{~F}$. Ao mesmo tempo 
390 A produtividade científica tem sexo?

cresce a proporção daqueles com menos de 50 anos, especialmente entre os bolsistas homens. Em termos gerais esse conjunto de PQs, que soma 941 em 2001, alcançando 1.571 em 2012 (crescimento de 67\%), a consolida como área em expansão no cenário atual da ciência brasileira.

\section{Gráficos 10 e 11 - Número absoluto de bolsas produtividade em Ciências Agrárias ${ }^{32}$, segundo sexo e idade do bolsista}

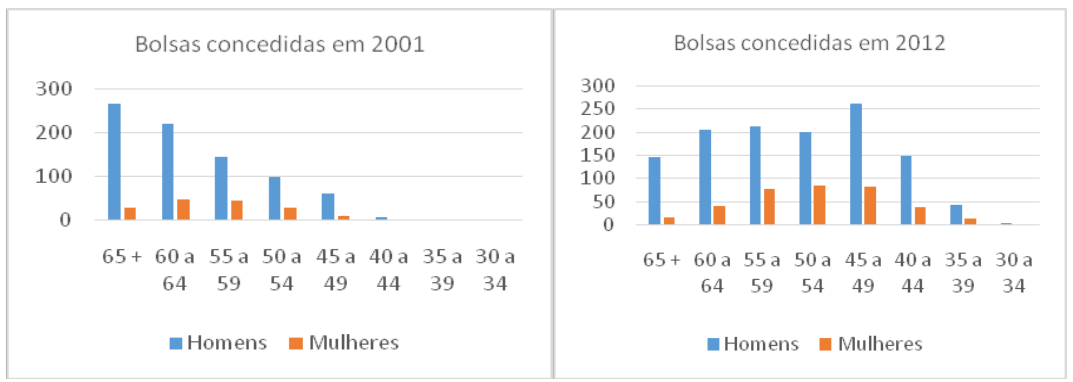

Fonte: $\mathrm{CNPq} / \mathrm{AEI}$. Elaboração própria.

Quando analisada internamente, a população feminina cresce um pouco mais do que a masculina em função de um patamar anteriormente muito baixo. Dentre as grandes áreas reconhecidamente masculinizadas, essa é a que apresenta o maior movimento de feminização, com a proporção de mulheres passando de $16,1 \%$ para $22,1 \%$. Nos bolsistas com menos de 50 anos a proporção de mulheres é de $22,38 \%$, similar ao contingente total de bolsistas nessa grande área.

Em relação às áreas que a compõem há certa homogeneidade nos dados observados: os homens continuam ampla maioria dos bolsistas, mas é clara a tendência de expansão das pesquisadoras, sugerindo um cenário em movimento, evidenciado nas duas maiores áreas: Agronomia (em que o peso

${ }^{32}$ Composta por: Agronomia, Medicina Veterinária, Meio Ambiente e Agrárias, Recursos Florestais e Engenharia Florestal, Recursos Pesqueiros e Engenharia de Pesca, Zootecnia. 
relativo feminino passa de $14,1 \%$ para $20,3 \%$ ) e Medicina Veterinária (de $23,8 \%$ para $28,2 \%$ ).

No conjunto de áreas que compõem as CIÊNCIAS HUMANAS encontramos grande diversidade de distribuições por sexo entre os bolsistas produtividade, cuja heterogeneidade dificulta a análise agregada. O número de PQs como um todo cresceu 82,4\% - 866 (2001) e 1.581 (2012) -,expansão razoável quando comparada à de outras áreas.

\section{Gráficos12 e 13 - Número absoluto de bolsas produtividade em Ciências Humanas ${ }^{33}$, segundo sexo e idade do bolsista}

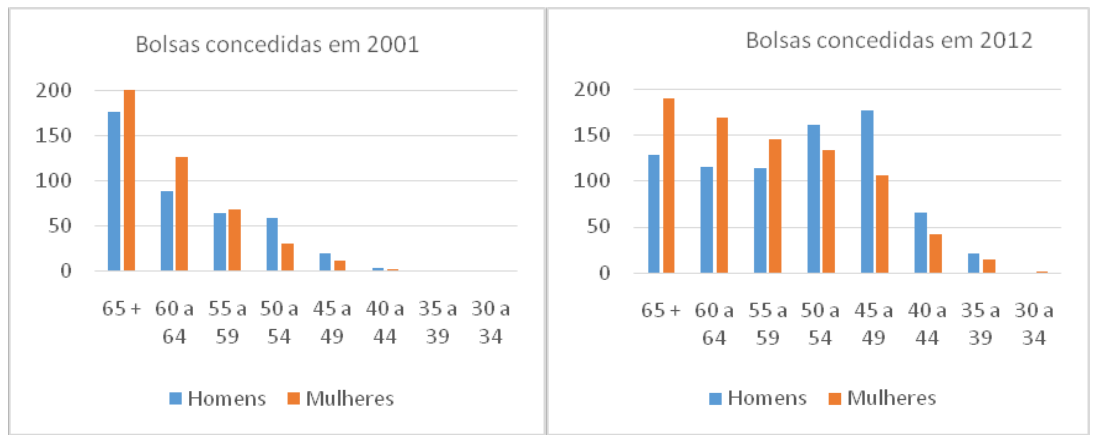

Fonte: $\mathrm{CNPq} / \mathrm{AEI}$. Elaboração própria.

Em 2001, percebemos uma clara hierarquia na qual a idade é elemento fundamental. Cresce o número de PQs nos grupos etários mais velhos, e pouquíssimos pesquisadores jovens são bolsistas. Em 2012, os bolsistas de idade mais avançada perdem peso relativo, mas os mais jovens continuam com acesso restrito, apresentando crescimento moderado, diferente do de outras áreas. O peso dos mais jovens, que já era baixo em 2001 (4,2\%), continua baixo em 2012, alcançando apenas 27\%. Dentro desse crescimento tímido do segmento mais jovem, os bolsistas homens

${ }^{33}$ Composta por: Antropologia, Arqueologia, Ciência Política, Educação, Filosofia, Geografia, História, Sociologia, Teologia, Psicologia. 
avançam mais e passam a ser maioria nos grupos etários de 35 a 54 anos.

No montante total, um relativo equilíbrio por sexo favorece ligeiramente as mulheres - 52,5\% em 2001 e 50,6\% em 2012. Isso se mantém ao longo do período, e o ligeiro rejuvenescimento dos bolsistas ocorre em ambos os sexos. Chama a atenção, no entanto, a intensa queda na proporção de mulheres no contingente de bolsistas com menos de 50 anos, que alcança $38,3 \%$ em 2012. É interessante notar que até os 54 anos os homens são maioria, e essa tendência se inverte nos grupos etários mais velhos, majoritariamente femininos.

Contudo, por se tratar de um conjunto composto por tendências muito diferentes entre si, os dados agregados não espelham bem a realidade. O peso da área de Educação é desproporcional em relação ao das demais, o que falsamente sugere uma feminização das CIÊNCIAS HuMANAS. O patamar de PQs concedidas à Educação já era muito superior, e essa diferença se ampliou em 2012, quando 362,8 PQs são oferecidas. Desse total, $62,7 \%$ foram destinadas a pesquisadoras mulheres. Essa diferença tão favorável ao contingente feminino só é observada na área de Psicologia, que passa de 59,9\% em 2001 para 63\% em 2012. Nas demais o que se observa é uma tendência contrária, com expressiva queda no peso relativo de bolsistas mulheres no período analisado. O quadro mais dramático é observado na Ciência Política, em que a proporção cai de $46,5 \%$ para $33,7 \%$. O mesmo acontece em História (de $54,8 \%$ para $48 \%$ ), Sociologia (de $53,1 \%$ para $47 \%$ ), Geografia ( $52,6 \%$ para $45,4 \%$ ). A Filosofia é a única área com baixíssima proporção de mulheres, e assim permanece ao longo do período, alcançando em 2012 apenas $16,6 \%$ do total de PQs oferecidas.

Esse quadro contrasta com o cenário mais amplo de expansão da presença feminina no quadro de bolsistas produtividade do CNPq. Se levarmos em conta que nos segmentos mais jovens os homens são maioria em 2012, podemos supor que, no caso das CIÊNCIAS HUMANAS, eles são os principais beneficiados com a recente expansão na concessão de bolsas categorias 2 e $2 \mathrm{~F}$. 
As CIÊNCIAS SOCIAIS APLICADAS foram historicamente contempladas com poucas PQs se considerada a ampla gama de áreas que compõem a área. $\mathrm{O}$ crescimento relativo desse montante é alto: $91,2 \%$, de 430 para 822 PQs ao longo do período. Outra característica marcante desse grupo de bolsistas é a distribuição relativamente equilibrada de homens e mulheres em todas as idades, com exceção dos mais jovens, até 40 anos, em que há clara diferença favorável aos homens. Até os 50 anos esse padrão predomina, e a maioria é masculina. Em linhas gerais a proporção de mulheres bolsistas se manteve em um patamar de $40 \%$ (alto, mas com poucos avanços ao longo do tempo). No contingente mais jovem (menos de 50 anos), o peso relativo feminino é bastante menor e alcança apenas $31,2 \%$ dos bolsistas em 2012. Como observado em diversas áreas, há um rejuvenescimento dos bolsistas como grupo, independentemente do sexo, passando de $10,3 \%$ para $36,4 \%$ o peso dos bolsistas com menos de 50 anos em 2012.

\section{Gráficos 14 e 15 - Número absoluto de bolsas produtividade em Ciências Sociais Aplicadas ${ }^{34}$, segundo sexo e idade do bolsista}

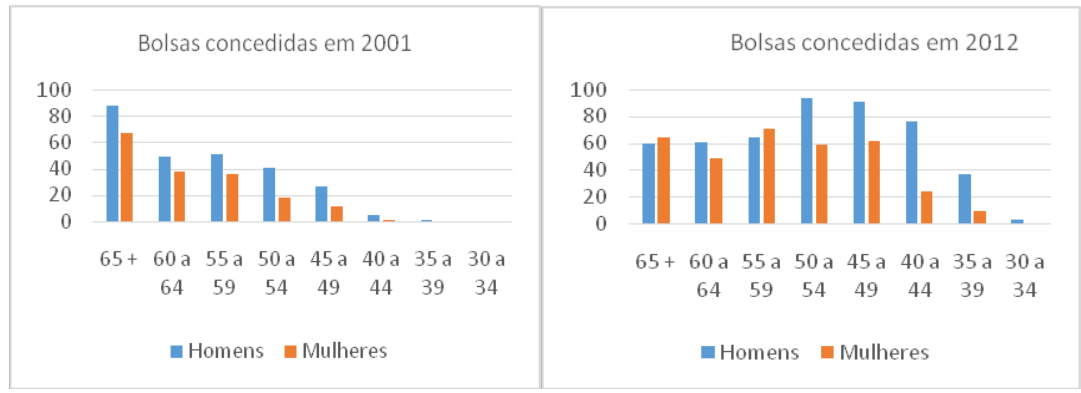

Fonte: $\mathrm{CNPq} / \mathrm{AEI}$. Elaboração própria.

\footnotetext{
${ }^{34}$ Composta por: Administração, Arquitetura e Urbanismo, Comunicação, Demografia, Desenho Industrial, Direito, Economia, Museologia, Economia Doméstica, Planejamento Urbano e Regional, Serviço Social, Turismo.
} 
Assim como nas ClÊNCIAS HUMANAS, nas CIÊNCIAS SOCIAIS APLICADAS o conjunto de dados é heterogêneo, o que limita a análise construída de forma agregada. Em áreas como Administração e Economia, a proporção de mulheres já baixa em $2001-36,7 \%$ e $18,8 \%$, respectivamente - diminui ainda mais: a primeira cai para $31,7 \%$ e a segunda para $12,4 \%$. O grande avanço feminino é observado na Comunicação, em que o peso relativo das bolsistas mulheres salta de $34,2 \%$ para $54,4 \%$. As demais áreas que a compõem têm um patamar mais reduzido de PQs, tornando desproporcionalmente alto o peso de uma bolsa, como é o caso do Serviço Social, com 69,2 bolsas em 2012, das quais 59,4 $(85,8 \%)$ de mulheres.

A grande área de LINGUístiCA, LETRAS E ARTES, histórico nicho feminino, é a menor de todas em montante de PQs. Nos gráficos nota-se distribuição semelhante entre os anos pesquisados, com alta concentração de pesquisadores nas idades mais avançadas. $\mathrm{O}$ peso relativo dos bolsistas com menos de 50 anos passa de 3,3\% para $20,7 \%$ em 2012. Esse crescimento é menor do que o de outras áreas, e o patamar que já era baixo em 2001 continua baixo no final do período analisado. O grupo etário com maior número de bolsistas em 2012 é o mais velho (65 anos ou mais). Chama a atenção, nesse sentido, o reduzido reconhecimento de pesquisadores jovens: como demonstra o gráfico, dificilmentese acessaa PQ com menos de 50 anos. 
Gráficos 16 e 17 - Número absoluto de bolsas produtividade em Linguística, Letras e Artes ${ }^{35}$ segundo sexo e idade do bolsista

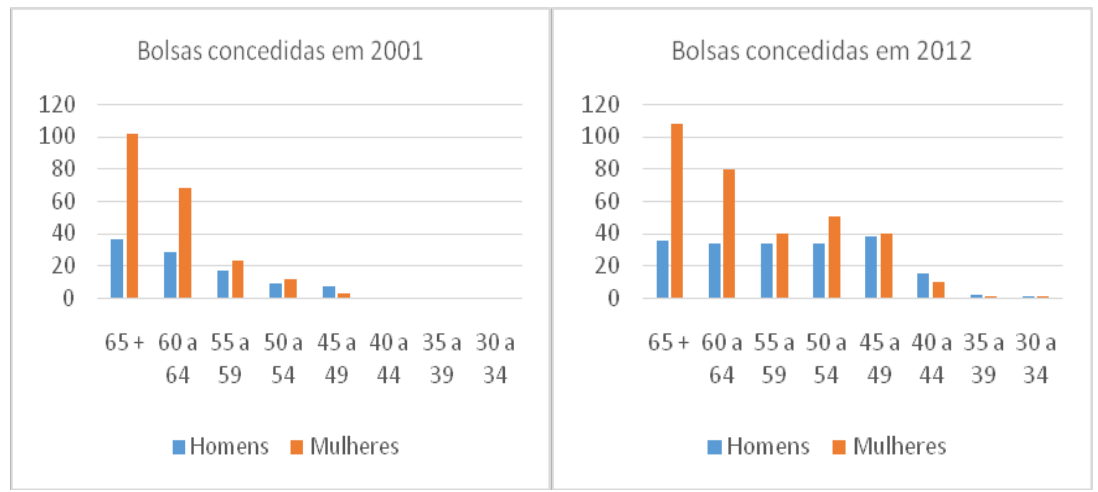

Fonte: $\mathrm{CNPq} / \mathrm{AEI}$. Elaboração própria.

Apesar de o total de PQs ter aumentado pouco, de 104 em 2001 para 521 em 2012, os jovens não foram os principais contemplados, sejam eles homens ou mulheres. Ao longo do período, o peso relativo das bolsistas mulheres cai de $67,9 \%$ para $63,3 \%$. No contingente com até 50 anos o peso relativo das mulheres cai para $48,1 \%$, como se constata no gráfico de 2012 , quando os homens representam a maioria dos bolsistas até o grupo etário 40 a 44 anos, e estão praticamente empatados com as mulheres no grupo 45 a 49 anos.

Esse fenômeno pode ser observado na análise dos dados por áreas: em Letras o peso de bolsistas mulheres cai de 64,3\% em 2001 para 57,5\% em 2012, e em Linguística essa proporção diminui de $77,5 \%$ para $72,4 \%$ no final do período. Já no caso de Artes, com montante de PQs consideravelmente menor, há ligeiro aumento na proporção de mulheres, de $56,2 \%$ para $58,1 \%$.

${ }^{35}$ Composta por: Artes, Letras e Linguística. 


\section{Considerações finais}

Apesar de a bolsa produtividade em pesquisa (PQ) do CNPq ter sido concebida nos anos 1970, observa-se na última década a sua transformação em uma carreira particular, a qual emerge no cenário de uma política pública cujo efeito mais amplo é o aprofundamento daautonomia dos grupos científicos brasileiros (Carlotto, 2013).

Como assinala a literatura aqui revisada, é fundamental para a análise do perfil do bolsista produtividade considerar a diversidade entre as áreas de conhecimento. $\mathrm{Na}$ análise que empreendemos, essa perspectiva, conjugada com as variáveis idade e sexo, mostrou-se extremamente fértil e permitiu desvelaras diferenças e semelhanças que caracterizam as culturas institucionais, habitualmente ocultadas sob o rótulo generalizante com que são definidas as grande áreas pelas agências de fomento. Contribuiu ainda para a percepção da $\mathrm{PQ}$ como um sistema dinâmico que, no tocante ao ingresso de mulheres nesse seleto grupo de pesquisadores, induziu, ao mesmo tempo, a mudanças e a continuidades.

Ressalta em primeiro lugar o peso diferenciado de cada uma quanto ao montante total de PQs, sendo as áreas mais contempladas as das CIÊNCIAS EXATAS E DA TERRA e ENGENHARIAS. A concentração de $\mathrm{PQs}$ nessas áreas provoca uma desproporção em geral na presenca de mulheres entre os bolsistas produtividade, uma vez que é justamente ali que se reproduz historicamente o fenômeno da baixa representação feminina. As exceções a essa tendência histórica nessas áreas com predomínio masculino, como Química, Engenharia Sanitária e Engenharia Química, constituem casos que merecem investigação específica a respeito das dinâmicas institucionais recentes que propiciaram a alteração desse quadro, com a elevação do número de bolsistas mulheres.

Outro caso de mudança é o das CIÊNCIAS AGRÁRIAS, campo tradicionalmente masculino, em cujo movimento de expansão de $67 \%$ no número de PQs no período 2001-2012 constatamos sinais inovadores de abertura ao ingresso de pesquisadoras. 
Alterações importantes também foram verificadas nas CIÊNCIAS BIOLÓGICAS e nas CIÊNCIAS DA SAÚDE, áreas com patamares mais equânimes e nas quais é franca a tendência de crescimento na proporção de bolsistas mulheres. Já nas CIÊNCIAS HUMANAS e em LINGUÍSTICA, LETRAS E ARTES houve, com algumas exceções, diminuição da histórica predominância feminina.

Quanto ao perfil etário, constatou-se o rejuvenescimento dos bolsistas produtividade em todas as grandes áreas. A maior abertura aos bolsistas jovens foi observada nas áreas que contam com maior montante de PQs - as CIÊNCIAS AGRÁRIAS, CIÊNCIAS EXATAS E DA TERRAe ENGENHARIAS. Nesse sentido, sobressai um aspecto fundamental: apesar de a oferta de bolsas nas categorias 2 e $2 \mathrm{~F}$, que constituem a porta de entrada do sistema, ter mais que dobrado, os homens jovens foram os principais beneficiados.

Uma conclusão geral baseada nos dados estatísticos analisados é que o fenômeno da predominância numérica dos homens entre os detentores de $\mathrm{PQ}$ do $\mathrm{CNPq}$ se deve à combinação de dois fatores: a elevada quantidade de bolsas destinadas às áreas CIÊNCIAS EXATAS E DA TERRA $e$ ENGENHARIAS $e$ o tradicional $e$ persistente perfil masculino dessas áreas. É possível, então, inferir que os critérios politíco-institucionais, que definem as áreas prioritárias às quais se destina o maior número de $\mathrm{PQ}$, têm produzido continuamente, no período 2001-2012, efeitos desfavoráveis às mulheres.

\section{Referências bibliográficas}

Alves, A.; YANASSE, H.; SOMA, N. Perfil dos bolsistas produtividade das áreas de engenharia de produção e de transportes do CNPq: enfoque na subárea de pesquisa operacional. In: Anais do XLIII Simpósio Brasileiro de Pesquisa Operacional, Ubatuba, São Paulo, vol. 8, 2011, pp.144-155.

Barata, R.; GoldBaum, M. Perfil dos pesquisadores com bolsa de produtividade em pesquisa do $\mathrm{CNPq}$ da área de saúde coletiva. Rio de Janeiro, Cadernos de Saúde Pública 19(6), 2003, pp.1.863-76. 
398 A produtividade científica tem sexo?

Bourdieu, P. O campo científico. In: OrTIZ, Renato (org.). Pierre Bourdieu. Sociologia. São Paulo, Ática, 1983, pp.122-155.

CENTRO de Gestão de Estudos Estratégicos (CGEE). Doutores 2010: estudos da demografia da base técnico-científica brasileira. Brasília, Centro de Gestão de Estudos Estratégicos (CGEE), 2010, p.41.

CARLOTTO, M. C. Veredas da mudança na ciência brasileira: discursos, institucionalização e práticas no cenário contemporâneo. São Paulo, Associação Filosófica Scientiae Studia/Editora 34, 2013.

CAVAlCANTE, R. et al. Perfil dos pesquisadores da área de odontologia no Conselho Nacional de Desenvolvimento Científico e Tecnológico (CNPq). São Paulo, Revista Brasileira de Epidemiologia 11(1), 2008, pp.106-13.

FERREIRA, M; MOREIRA, R. L. (orgs.). CAPES, 50 anos: depoimentos ao CPDOC/FGV. Brasília, Capes, 2002.

HEINZ, F. (org.). Por outra história das elites. Rio de Janeiro, Editora FGV, 2006.

Hostins, R. Os Planos Nacionais de Pós-Graduação (PNPG) e suas repercussões na pós-graduação brasileira. Florianópolis, Perspectiva 24(1), 2006, pp.133-60.

LEITE, B. et al. Perfil dos pesquisadores com bolsa de produtividade no Conselho Nacional de Desenvolvimento Científico e Tecnológico (CNPq) da área da educação física. Portugal, Edições Desafio Singular, Motricidade 8(3), 2012, pp.90-8.

LiMA, R.; VelHO, L.; FARIA, L. Bibliometria e avaliação da atividade científica: um estudo sobre o índice h. Belo Horizonte, Perspectivas em Ciência da Informação 17(3), 2012, pp.3-17.

MENDES, P. et al. Perfil dos pesquisadores bolsistas de produtividade científica na medicina no CNPq, Brasil. Rio de Janeiro, Revista Brasileira de Educação Médica 34(4), 2010, pp.535-41.

MERTON, R. O efeito Mateus na ciência II: a vantagem cumulativa e o simbolismo da propriedade intelectual. In: MARCOVICH, Anne; SHINN, Terry (orgs.). Robert Merton. Ensaios de sociologia da ciência. São Paulo, Associação Filosófica Scientiae Studia/Editora 34, 2013, pp.199-231. 
OlinTO, G. Mulheres e jovens na liderança da pesquisa no Brasil: análise das bolsas de pesquisador do CNPq, 2003 [http://ridi.ibict.br/handle/123456789/320 - acesso em: 22 ago. 2014].

OliveIRA, A.; BiANCHETTI, L. CNPq: política de fomento à pesquisa nos governos Fernando Henrique Cardoso (FHC). Florianópolis, Perspectiva 24(1), 2006, pp.161-82.

OliveIRA, E. et al. Pesquisadores do Conselho Nacional de Desenvolvimento Científico e Tecnológico na área de Cardiologia. Rio de Janeiro, Arquivos Brasileiros de Cardiologia 97(3), 2011, pp.186-93.

SANTOS, N.; CÂNDIDO, L.; KuPPENS, C. Produtividade em pesquisa do CNPq: análise do perfil dos pesquisadores da química. São Paulo, Química Nova, 33(2), 2010, pp.489-95.

SANTOS, S. M. C. et al. Perfil dos pesquisadores da Saúde Coletiva no Conselho Nacional de Desenvolvimento Científico e Tecnológico. Rio de Janeiro, Physis 19(3), 2009, pp.761-75.

SPILKI, F. Perfil dos bolsistas de produtividade do Conselho Nacional de Desenvolvimento Científico e Tecnológico (CNPq) na área de medicina veterinária. Rio de Janeiro, Pesquisa Veterinária Brasileira 33(2), 2013, pp.205-13.

WAINER, J.; VIEIRA, P. Avaliação de bolsas de produtividade em pesquisa do $\mathrm{CNPq}$ e medidas bibliométricas: correlações para todas as grandes áreas. Belo Horizonte, Perspectivas em Ciência da Informação 18(2), 2013, pp.60-78.

Wendt, G. et al. Perfil dos Bolsistas de Produtividade em Pesquisa do CNPQ em Psicologia. Brasília, Psicologia: ciência e profissão 33(3), 2013, pp.536-47. 